\title{
Evolução histórica e o quadro socioeconômico do Nordeste brasileiro nos anos $2000^{1}$
}

Hugo Feitosa Gonçalves ${ }^{2}$ José Bezerra de Araújo ${ }^{3}$

\section{Resumo}

O presente estudo tem como objetivo apresentar, de forma breve, a trajetória socioeconômica do Nordeste brasileiro, desde a chegada dos europeus nas terras brasileiras, no final do século $\mathrm{XV}$, até o fim da primeira década do século atual, visando proporcionar uma maior familiaridade do leitor com o assunto em uma leitura compacta. Com uma intenção exploratória, o procedimento metodológico da pesquisa baseia-se em uma revisão bibliográfica e documental, de caráter quali-quantitativo. O trabalho, em seu primeiro momento, trata da "Questão Nordeste", eclodida em meados do século $X X$, que perdura até os dias atuais. O ponto seguinte mostra, de uma forma resumida, a formação econômica dessa região, que vai desde o período inicial da exploração e colonização da região nordestina e brasileira até o final da década de 1990. Conclui-se apresentando dados quantitativos, com a intenção de caracterizar a situação macroeconômica e sua relação com as mudanças sociais da região Nordeste, nos anos 2000, tomando como base os indicadores nacionais.

Palavras-chave: Nordeste. Formação Econômica. Desenvolvimento Social.

\begin{abstract}
This study aims to survey on the economic and social trajectory of the Brazilian Northeast, since the arrival of Europeans to the Brazilian territory in the late fifteenth century to the end of the first decade of the present century, seeking to provide greater reader's familiarity with the subject in a compact reading. With an exploratory intent, the methodological research procedure is based on a bibliographical and documentary review of qualitative and quantitative character. The work on their first time deals with "question northeast," appeared in the mid-twentieth century that continues to these days. The following section shows briefly the economic formation of this area stretching from the early period of exploration and colonization of the Northeastern region of Brazil by the end of 1990. Concludes presenting quantitative data with the intention of characterizing the macroeconomic situation and its relationship with the social changes of the Northeast in the 2000s, based on national indicators.
\end{abstract}

Keywords: Northeast. Economic Growth. Social Development.

\footnotetext{
${ }^{1}$ Texto expandido do artigo apresentado no GT 1 - Estado, Planejamento e Políticas Públicas de Desenvolvimento Regional - do II SEDRES, sediado Campina Grande (PB) entre os dias 13 e 15 de agosto de 2014.

${ }^{2}$ Mestrando em Desenvolvimento Regional na Universidade Estadual da Paraíba (UEPB). hugofg@live.com

${ }^{3}$ Doutor em Ciências Econômicas. bezerraraujo@uol.com.br
} 


\section{Introdução}

No relatório que precedeu o surgimento da Superintendência do Desenvolvimento do Nordeste (SUDENE), o grupo coordenado por Celso Furtado indicou que um dos principais problemas da economia nordestina, nos anos de 1940 e 1950, era a tendência do capital produtivo ir em direção ao Centro-Sul do Brasil, devido ao maior dinamismo industrial e à eficiência do capital implantado naquela região, proporcionando um aumento na lucratividade dos investimentos. No início da década de 1960, a SUDENE, em seus primeiros anos, destinou recursos federais para o desenvolvimento da logística e para a área de recursos naturais, impulsionando o desenvolvimento econômico dessa região nas décadas seguintes (ARAÚJO, 2000). Mas, a partir de 1964, a SUDENE limitouse basicamente a proporcionar facilidades de investimentos, favorecendo os grandes capitalistas e esquecendo os pequenos empresários, abandonando, assim, a ideia inicial de um desenvolvimento homogêneo.

Segundo Araújo (2000, p. 172), “[...] nas diversas regiões brasileiras o Estado patrocinou fortemente o crescimento econômico. Porém, o Nordeste, pode-se afirmar que sua presença foi o fator determinante de intensidade e dos rumos do dinamismo ocorrido nas últimas décadas".

Mas, como mostrou Prado Júnior (1994), em seu livro "História Econômica do Brasil", a economia da Região Sudeste, em seu período inicial como potência produtiva final do século XIX e início do século XX - e comercial (posto que ocupa até os dias atuais) manteve-se firme, devido, entre outros fatores, ao financiamento da produção cafeeira e da estrutura comercial realizado pelo poder público. Assim, não se pode tomar essa menção de Tânia Bacelar de Araújo como sendo uma questão contemporânea e isolada.

Para se ter uma noção da questão Nordeste na contemporaneidade, pode-se tomar como base alguns dados. Em 2011, o Jornal Folha de São Paulo, baseado em dados do Instituto Brasileiro de Geografia e Estatística (IBGE), divulgou uma matéria mostrando que o Nordeste concentrava $59 \%$ da população do País em extrema pobreza (FOLHA DE SÃO PAULO, 2011). Apesar do grande número de indigentes vivendo nas áreas urbanas, a questão social, nas zonas rurais, era mais grave no início do século XXI (como em boa parte do País).

A estagnação das estruturas sociais rurais era basicamente financiada pelo Governo Federal, através da Previdência Social, que assegurava a sobrevivência de grande parte das famílias rurais, principalmente no sertão. Com as secas constantes, os pequenos produtores foram obrigados a vender suas terras a baixos preços, concentrando a maior parte das terras nas mãos de poucos latifundiários, ampliando a desigualdade no campo. Segundo o Instituto de Pesquisa Econômica Aplicada (IPEA), no ano de 2000, o Nordeste abrigava dois terços dos indigentes rurais do Brasil (ARAÚJO, 2000).

Portanto, a presente pesquisa busca, principalmente, observar e descrever as condições socioeconômicas da população nordestina, na primeira década do século XXI. Serão analisadas algumas das variáveis econômicas e sociais mais enfatizadas pelos representantes do governo e meios de comunicação, na tentativa de alocar a situação socioeconômica contemporânea do Nordeste em sua trajetória histórica. Busca-se diferenciar a situação macroeconômica das questões sociais, pois, na maior parte da literatura 
tradicional sobre esse tema, as condições sociais foram colocadas como diretamente proporcionais ao quadro macroeconômico.

Para entender a vigente estrutura econômica e social do Nordeste, é necessário conhecer a evolução histórica dessa região. O artigo baseia-se em um estudo exploratório realizado a partir de uma pesquisa bibliográfica e documental, com descrições quali-quantitativas. Um breve texto publicado em 1997, "Trajetória Econômica do Uma Região Periférica", de Leonardo Guimarães, será a base para mostrar a formação socioeconômica do Nordeste, complementado por outras publicações, como a de sua própria autoria com Carlos Antonio Brandão, a de Caio Prado Júnior, mais artigos de Jair do Amaral Filho e José Elesbão de Almeida, em parceria com José Bezerra de Araújo, entre outros. Ressalte-se que os cortes temporais seguem a proposta de Guimarães Neto, que tomou como base as denominações de Celso Furtado.

\section{Formação econômica nordestina}

O período inicial da história do Nordeste, após a chegada dos europeus em suas terras, está diretamente ligado com o início da formação econômica do território brasileiro, pois o conhecimento e a exploração (dos povos não nativos) do território que hoje abrange a República Federativa do Brasil começou por essa região localizada ao norte do País, banhada pelo Oceano Atlântico.

Em meados do século XVI, época de povoamento e colonização efetiva do território brasileiro, as primeiras mudas de cana-de-açúcar, trazidas de Portugal, foram plantadas e cultivadas no espaço que hoje compõe parte do Nordeste, principalmente nas áreas litorâneas da região, que hoje pertencem aos Estados da Bahia e Pernambuco. Com base inicialmente no trabalho pago de indígenas, que logo foi substituído por mão de obra escrava (composta por africanos e índios nacionais), a exploração da cana-de-açúcar, que era praticamente voltada para abastecer o mercado europeu, foi, na época, a produção mais lucrativa da Coroa portuguesa, dando início às atividades exploratórias da região, com produções voltadas ao mercado externo. Nesse período, a capital do Brasil era a cidade de Salvador, devido à região Nordeste ser a mais dinâmica e moderna do país (GUIMARÃES NETO, 1997).

Como todas as atenções estavam voltadas para a produção do açúcar, devido à grande margem de lucro deixada por esse comércio, a produção de gêneros alimentícios, para abastecer a colônia, era ignorada. Com isso, grande parte dos colonos, principalmente os que viviam nas cidades, sofreu com a falta de alimentos (PRADO JÚNIOR, 1994, p. 43), surgindo a necessidade de desenvolver uma produção para a subsistência dos habitantes coloniais.

Feitosa (2013) cita vários autores, mostrando que, no período de grande produtividade da cana-de-açúcar, ainda no século XVI, surge outra atividade produtiva que foi a criação de gado, destinada a suprir as necessidades alimentares da população colonial, além de fornecer o couro para outras atividades. Furtado (1981) destacou que a invasão dos criatórios nas plantações fez com que essa produção fosse proibida pelo governo português na área litorânea, devido à ameaça dessa atividade à produtividade do açú- 
car, que apresentava um melhor desempenho comercial. Esses dois sistemas de produção - de açúcar e a pecuária - formaram o que foi denominado pelo autor de "Complexo Econômico Nordestino" (FURTADO apud FEITOSA, 2013).

$\mathrm{Na}$ falta de condições financeiras para bancarem a expansão dos engenhos de açúcar no Brasil, devido à grande demanda europeia, os portugueses foram buscar parcerias com os holandeses, atraindo-os para o território brasileiro. Na segunda metade do século XVII, os holandeses saíram (expulsos) das terras nordestinas e levaram com eles o conhecimento do cultivo da cana-de-açúcar. Em suas terras, eles empreenderam o cultivo aprendido e passaram a ofertar açúcar a um preço e qualidade com os quais o produto da Coroa portuguesa não conseguiu competir por muito tempo. Assim, aconteceu a primeira crise na produção da cana-de-açúcar no Brasil, que acarretou o fim do "ciclo-da-cana" (denominação do autor referenciado). Para Souza (2013), mesmo com o fim desse ciclo, a produção de açúcar continuou a figurar entre os produtos ofertados pela colônia.

Segundo Singer (1968), a crise econômica da atividade açucareira ganhou mais força com o início da exploração do ouro, no Centro-Sul do país, atraindo mão de obra e aumentado o preço dos escravos - base da produção do açúcar - e deslocando-os do comércio externo para essas áreas (SINGER apud FEITOSA, 2013).

Guimarães Neto (1997) ressalta que, além do ciclo da cana, foram desenvolvidas, na região Nordeste, sucessivas atividades de produção, como a de algodão (ganhando importância a partir da Primeira Revolução Industrial), fumo e cacau, voltadas todas para suprir a demanda externa.

Os produtores nordestinos tiveram que se adaptar constantemente às mudanças, à medida que outras regiões do mundo passaram a produzir os mesmos produtos, como o açúcar e o algodão, com qualidades superiores. Citando Cano, Guimarães Neto (1997) mostra que o declínio dos preços dos produtos nordestinos exportados e a dificuldade desses produtos de entrar no mercado nacional fizeram com que o Nordeste não apresentasse uma expansão da produção e, consequentemente, não acumulasse capital como no início do período colonial.

O aumento da produção e exportação do café, na região Sudeste, e a abolição da escravatura (principal força de trabalho utilizada no Nordeste), no final do século XIX, foram os principais fatores apontados como contribuintes da profunda crise ocorrida no setor exportador nordestino. Após o ápice da crise, o Nordeste começou a ocupar um espaço secundário na nova divisão do trabalho nacional (GUIMARÃES NETO, 1997).

O deslocamento do centro econômico brasileiro do Nordeste para o Sudeste aconteceu de maneira natural, devido à produção cafeeira ocupar o maior espaço nas transações econômicas no comércio nacional e externo. Furtado relata que, com grande poder representativo no governo nacional, os produtores de café defendiam seu produto, dentre outras maneiras, através de políticas públicas, como a desvalorização da moeda nacional e a destruição de estoques de café em períodos de desaceleração da demanda (FURTADO apud GUIMARÃES NETO; BRANDÃO, 2009).

Prado Júnior (1994) aponta os mesmos fatores relatados por Guimarães Neto em relação à grande desaceleração da economia nordestina, que, no período agora analisado, baseava-se ainda na exportação do produto da cana, e inclui um fator relevante, 
ao qual defende claramente como um dos determinantes para o desencadeamento da crise do setor, que foi o atraso na inovação da produção e na estrutura comercial desse produto, além de demonstrar implicitamente a falta de interesse dos governantes, tanto no período colonial quanto no império, com o desenvolvimento da produção e da economia dessa região.

Até a década de 1930, o território brasileiro era formado por mercados regionais independentes. Segundo Furtado, no início do período da "Articulação Comercial", a partir da década referida, com a formação do mercado nacional, as regiões brasileiras tinham alcançado diferentes graus de articulação comercial e econômica, e a desigualdade dos níveis de rendas entre as diversas regiões tinha aumentado. Na medida em que caíam os preços das commodities, devido ao aumento da concorrência nacional e mundial e à formação de um mercado de manufaturas mundial, os investimentos na indústria substituíam gradativamente os da produção cafeeira, aumentando a tendência de concentração industrial e de capital no Centro-Sul (FURTADO apud GUIMARÃES NETO; BRANDÃO, 2009).

O relatório do Grupo de Trabalho para o Desenvolvimento do Nordeste (GTDN) ${ }^{4}$ mostrou que, na década de sua divulgação - anos de 1950 - após um grande período de recessão do comércio agroexportador e de uma gradativa perda de participação do Nordeste na economia brasileira, essa região tornou-se uma das mais pobres do hemisfério sul. A renda média da população nordestina era menos de um terço da renda dos habitantes do Centro-Sul, sendo o produto do Nordeste bem mais concentrado, aumentando ainda mais a disparidade em relação às condições de vida dos habitantes dessas duas grandes regiões (GRUPO DE TRABALHO PARA O DESENVOLVIMENTO DO NORDESTE, 1997).

Para Guimarães Neto (1997), na segunda metade dos anos de 1950, as indústrias do Sudeste, em busca de novos mercados consumidores, invadiram o mercado nordestino, prejudicando a pequena indústria da região, como foi o caso do segmento têxtil. No governo de Juscelino Kubitschek, época de crise econômica no Nordeste, agravada por uma longa seca, cujo ápice foi em 1958, o aumento das disparidades sociais e econômicas entre o Centro-Sul e o Nordeste contribuiu para o crescimento de forças sociais e políticas que reivindicavam por políticas voltadas para mudanças estruturais na sociedade brasileira, as chamadas "reformas de base". Neste contexto, a questão regional ganhou destaque na política, de modo que se criaram instituições, medidas políticas e recursos, a fim de melhorar a situação socioeconômica dos nordestinos.

Diante das pressões populares, da Igreja Católica e de governantes estaduais, o então presidente Kubitschek criou, em 1956, o GTDN, com o intuito de realizar estudos para desenvolver a atividade econômica e afastar qualquer possibilidade de revolução na sociedade nordestina. O documento do GTDN apresentado à presidência da República mostrou, em suas primeiras páginas, que havia uma grande disparidade de renda entre o Nordeste e o Centro-Sul, causado por alguns fatores estruturais, como a concentração de renda, e ambientais, como as secas constantes e a escassez de terras aráveis,

${ }^{4}$ Documento divulgado no Governo de Juscelino Kubitscheck. Resumidamente, o texto faz uma análise das questões econômicas e sociais do Nordeste no período final da primeira metade do século XX. 
constituindo-se numa situação relevante que poderia ser minimizada (GRUPO DE TRABALHO PARA O DESENVOLVIMENTO DO NORDESTE, 1997).

Do relatório do GTDN, origina-se a SUDENE, em dezembro 1959, a qual, segundo a própria entidade, "representou uma das conquistas mais importantes do povo brasileiro, na história recente de nosso país, porque deu início a uma nova era, marcada pela incorporação progressiva da Região Nordeste" no processo de integração nacional realizado pelo governo federal, pois, na época, o dinamismo do crescimento econômico era restrito às regiões Sudeste e Sul (BRASIL, 2013).

Segundo Almeida e Araújo (2004), após a criação da SUDENE, o processo de industrialização da Região passou a ser defendido como condição fundamental para a inserção do Nordeste no processo de desenvolvimento do Brasil, além de diminuir a heterogeneidade econômica e social intrarregional.

Paradoxalmente, a Sudene contribuiu diretamente para que esse processo se consumasse nos padrões de verticalização e dependência da economia nordestina em relação à hegemonia burguesa do Sudeste do país, concentrada no entorno de São Paulo. [...] o Nordeste assumiu uma 'nova função' no processo de complementaridade da acumulação de capital em favor da burguesia industrial do Sudeste (ALMEIDA; ARAúJO, 2004, p. 110).

No início da fase da "Integração Produtiva" - década de 1960 -, a recém-fundada SUDENE focou os estudos principalmente nos dotes de recursos minerais da Região e dirigiu recursos financeiros públicos para a ampliação da infraestrutura, basicamente em transportes e energia elétrica. No mesmo período, incentivos fiscais, como o Fundo de Investimento no Nordeste (FINOR), investimentos de empresas estatais, como o caso da PETROBRAS, no estado da Bahia, e da Vale do Rio Doce, no estado do Maranhão; créditos de bancos públicos de desenvolvimento e capitais privados locais, nacionais e multinacionais impulsionaram o crescimento econômico do Nordeste, como foi o caso do novo parque industrial, que contou com o apoio de incentivos públicos para a sua instalação, o que aumentou a interligação econômica dessa região com outras da federação brasileira, sobretudo com o Sudeste (ARAÚJO, 2000).

Esses impulsos tiveram como resultado um crescimento econômico nordestino perto da média do Brasil entre 1960 e 1975. Após o primeiro choque do petróleo, em meados dos anos de 1970, enquanto a atividade econômica brasileira desacelerou, o Produto Interno Bruto (PIB) do Nordeste passou a crescer em um nível acima do nacional. Guimarães Neto (1997) apontou dois pontos imprescindíveis para compreender o processo de crescimento econômico nordestino neste período: o primeiro foi a seletividade do capital empreendido, alocado apenas nas áreas e segmentos mais dinâmicos; o segundo seria a industrialização tardia da região Nordeste em relação ao Sudeste, colocando a primeira região apenas como uma alternativa para ocupação dos espaços econômicos permitidos pelo capital industrial da segunda. Assim, algumas áreas de dinamismo econômico nordestinas coexistiram com áreas de estagnação produtiva.

Em 1964, o golpe militar abandonou o debate das propostas elaboradas no governo de João Goulart. Os governos militares tinham como objetivo restaurar o domínio das classes conservadoras e colocar o Brasil entre as grandes potências econômicas mundiais a qualquer custo social. Nesse período, a proposta de reforma agrária também 
foi arquivada, e a questão fundiária permaneceu praticamente inalterada. Essa inércia reformista no campo por parte dos governantes dificultou ainda mais o desenvolvimento no Nordeste, pois haveria uma grande concentração de terras nessa região, e a miséria, nas áreas rurais nordestinas, seria a mais grave do Brasil (ARAÚJO, 2000).

A proposta de acelerar o crescimento econômico a qualquer custo foi defendida pelo ex-ministro dos governos militares e principal idealizador da política nacional da época, o economista Delfim Netto, que comparou o crescimento econômico nacional a um bolo que precisava primeiro crescer para depois ser dividido. Na época, o Brasil se tornava a oitava base industrial do mundo à custa de uma grande desigualdade social dentro das regiões e inter-regional (ARAÚJO, 2000).

O projeto desenvolvimentista brasileiro, como na maior parte da América latina, foi extremamente conservador, autoritário e, consequentemente, antissocial. Segundo Veiga (2010), essa ideia do bolo a ser repartido não pode ser aceita pela sociedade, porque, além de não se realizar na prática, ainda fere os princípios éticos. Neste mundo de grandes desigualdades, não se pode esperar que os ricos se tornem ainda mais ricos para que, depois, os pobres fiquem um pouco menos pobres.

A estrutura econômica nacional promoveu a indústria nordestina, a fim de prolongar o desenvolvimento da indústria do Centro-Sul, ignorando, de certa forma, a cultura de produção da região. Explica-se, assim, a baixa rentabilidade do capital investido no Nordeste. Nessa região, da mesma forma como aconteceu com a oferta industrial, a demanda de bens de consumo também teve de adaptar-se aos produtos da indústria do Sudeste. "A nova dependência reside exatamente na subordinação à lógica de uma industrialização que abarca o conjunto do País e é comandada do Centro-Sul" (FURTADO, 1981, p. 14).

Nos anos de 1970, a partir das medidas elaboradas no II Plano Nacional de Desenvolvimento (PND), o governo federal brasileiro realizou um grande programa de investimentos públicos, mantendo o dinamismo econômico do Brasil num quadro de crise financeira mundial. As grandes empresas estatais implantadas no Nordeste seguiram a tendência nacional e aumentaram seus investimentos na região. Nesse período, a participação do Nordeste como recebedor de recursos financeiros federais e de empresas estatais, alocados em capital fixo, passou a aumentar. Acompanhando o crescimento das exportações brasileiras, o Nordeste passou a aumentar significantemente o seu volume exportado (ARAÚJO, 2000). Esse pequeno processo de desconcentração, como mencionou Carlos Américo Pacheco (apud ARAÚJO, 1999), não beneficiou todas as sub-regiões do Nordeste; na verdade, os novos capitais foram investidos nos setores e áreas mais promissores(as), denominados(as) de "ilhas de prosperidade", contribuindo para o aumento da heterogeneidade inter e intrarregional.

Após o primeiro choque do petróleo, em 1973, a economia brasileira diminuiu o seu ritmo de crescimento de $11 \%$ ao ano para a média de 7\%, entre 1974 e 1980; enquanto isso, a produção nordestina cresceu em média 7,4\% no mesmo período (ARAÚJO, 2000).

A redemocratização do Estado brasileiro, na década de 1980, veio num período de recessão econômica nacional, em razão da dívida externa, decorrente da política econômica praticada anteriormente, e do ajuste patrimonial empreendido, que inter- 
rompeu também o financiamento das políticas de desenvolvimento regional (ALMEIDA; ARAÚJO, 2004).

Nesse período, visto como fase pré-inicial do mundo globalizado, houve uma forte migração do capital público e privado para as regiões mais dinâmicas, revertendo o quadro de desconcentração espacial e setorial da indústria. As ideias neoliberais passam a emergir nos domínios brasileiros, e a indústria volta a concentrar-se nas áreas mais lucrativas, iniciando um período de guerra fiscal entre os estados para atrair os investimentos privados. A partir daí as políticas de integração nacional são arquivadas pelos governantes, e o capital segue a lógica de sobrevivência do mercado, localizando-se nas regiões e áreas mais aptas para o desenvolvimento das forças produtivas (COSTA, 2012).

De acordo com a mesma publicação de Costa, a década de 1990 - início da "Fase da Globalização" - foi marcada pela predominância das políticas neoliberais - abertura financeira e comercial, privatizações de empresas estatais, redução da atuação do Governo Federal, dentre outras - iniciadas a partir do Governo Collor. O Estado brasileiro deixou de fomentar a estrutura desenvolvimentista econômica das regiões periféricas, abandonando a proposta de integração nacional, abrindo as fronteiras do mercado nacional, prejudicando as indústrias em formação das regiões periféricas, inclusive a nordestina, que provocou a aceleração do processo de concentração industrial brasileiro.

Araújo (2000) fez um levantamento do ritmo de produção, entre as décadas de 1960 a 1990, relacionando os dados brasileiros com os do Nordeste. Os números mostram que, após o início da atuação da SUDENE, o PIB nordestino apresentou um desempenho próximo à média do Brasil, exceto entre 1967-1973, época do "milagre econômico brasileiro", quando a média do crescimento do produto nacional foi de $11,1 \%$, enquanto o do Nordeste cresceu 6,9\%.

Comparando as taxas de crescimento entre as décadas demonstradas por Tânia Bacelar de Araújo, nos anos de 1960, o PIB brasileiro cresceu em média 6,1\%, enquanto o PIB do Nordeste alcançou a média de 6,0\%; na década de 1970, as médias nacional e nordestina apresentaram o mesmo crescimento de $8,7 \%$. O período de recessão econômica nacional, os anos de 1980, mostrou o menor crescimento do período, tanto para a economia nacional quanto para a do Nordeste, mas o efeito recessivo da economia brasileira afetou em menor proporção os dados da produção nordestina, que cresceu, em média, 4,0\%, embora o produto do Brasil tenha crescido, em média, apenas 1,6\%.

Apesar da dinâmica econômica nordestina, apresentada nos dados anteriores, ter sido incentivada basicamente pelos gastos públicos, uma das marcas mais importantes do Nordeste continua sendo a privação humana, tanto em relação à renda quanto aos outros fatores geralmente envolvidos nas discussões sobre o desenvolvimento social. Araújo (2000) apresenta um levantamento do Instituto de Pesquisa Econômica Aplicada (IPEA) que mostra que, em 1990, 55\% dos indigentes brasileiros estavam no Nordeste, sendo que $63 \%$ desses indigentes viviam na zona rural, e por volta de $46 \%$ viviam no perímetro urbano.

O crescimento econômico do Nordeste, financiado pelo setor público e pelo capital externo, acarretou um dinamismo concentrado apenas em algumas áreas da região, aumentando a heterogeneidade econômica do espaço nordestino (GUIMARÃES NETO, 1997). 
Apesar da miséria predominando nas áreas rurais nordestinas, a questão fundiária continua esquecida pelos governantes, apesar da calamidade enraizada no campo. Na Zona da Mata, a concentração fundiária continua crescendo, e o cultivo da cana-de-açúcar amplia sua predominância. As secas do semiárido agravam a concentração das áreas na região, devido à inviabilização das terras nesses períodos, forçando os pequenos produtores a venderem suas propriedades a baixos preços para os grandes latifundiários (ARAÚJO, 2000), restando-lhes, geralmente, a escolha entre a pobreza do campo nordestino ou a migração para os centros urbanos.

Portanto, de acordo com o que foi apresentado até aqui, a região Nordeste passou de uma potência explorada pela Coroa portuguesa, no período de colonização e povoamento, para uma região heterogênea e periférica no mundo capitalista, passando a ser explorada pela região do Brasil que passou a concentrar o poder político e a renda desde o período final o Império. Apesar do crescimento do PIB da região Nordeste, entre os anos de 1960 e 1990, impulsionado pelos incentivos públicos, a participação média nordestina na formação do produto interno nacional permaneceu praticamente a mesma, comparando os dados dos anos 80 com os anos finais do século XX.

\section{Nordeste nos anos 2000}

De acordo com os dados do IBGE, o Nordeste atravessou os anos 2000 com uma participação média na formação do produto interno, igual ao observado nos anos de 1980 e 1999, patamar esse que é bem inferior aos observados nos anos de 1985 e 1990, que foram de $15 \%$ e $17 \%$, respectivamente, nos últimos anos citados. Com cerca de $27 \%$ da população nacional, essa região atingiu uma participação, na população formalmente ocupada brasileira, de 18,1\%, produzindo uma média de 13,1\% do PIB nacional (INSTITUTO BRASILEIRO DE GEOGRAFIA E ESTATÍSTICA, 2012), ficando evidenciado que a região Nordeste obtém uma baixa produtividade da sua mão de obra, indicando a necessidade de mais investimentos e, principalmente, planejamento e ações estruturais para educação e tecnologia nessa região.

Com base em dados da mesma publicação, pode-se afirmar que o Sudeste percorreu toda a década primária do século XXI produzindo mais da metade da riqueza nacional, enquanto o Nordeste permaneceu na terceira posição nesse ranking. Em relação ao crescimento do PIB, o Banco do Nordeste Brasileiro (BNB) mostrou que o Nordeste apresentou uma evolução maior que a média brasileira; enquanto a região cresceu $4 \%$ ao ano, entre 2001-2010, o Brasil evoluiu em média 3,7\%. Quando essa riqueza gerada é dividida aritmeticamente pelo número de habitantes, o patamar dessa evolução cai, passando a região Nordeste a ter um crescimento médio de $2,8 \%$, enquanto a evolução média nacional desse indicador foi de $2,4 \%$ ao ano (BANCO DO NORDESTE BRASILEIRO, 2012).

Esse desempenho nordestino, principalmente nos anos de 2009 e 2010, foi influenciado por um aumento dos gastos governamentais em obras infraestruturais, como as do Programa de Aceleração do Crescimento (PAC), iniciadas em 2006. Antes desse programa, observa-se que o crescimento médio do PIB do Nordeste foi de 3,4\%; após sua iniciação, esse número passou para 4,8\%. Essa variação positiva também se deu em âmbito nacional (BRASIL, 2010). 
Outros fatores que colaboraram com o desempenho econômico nordestino foram o aumento no limite de endividamento dos estados e municípios, entre 2006 e 2010; o crescimento das transações do comércio internacional; o aumento real do salário mínimo, pois essa é/era a região que abriga(va) mais trabalhadores que recebem salários mínimos; e os programas assistencialistas, como o Bolsa-Família (AMARAL FILHO, 2010; BANCO DO NORDESTE BRASILEIRO, 2012; BRASIL, 2010).

O dinamismo econômico da região também depende da grande quantidade de transferências financeiras, recebidas através de fundos federais para os estados e municípios, de programas sociais federais, como Bolsa-Família (como já foi relatado), de benefícios da Previdência Social, entre outros. Em 2008, o programa Bolsa-Família destinou mais de $52 \%$ dos seus benefícios para o Nordeste, atendendo aproximadamente à metade da população beneficiada pelo programa. No geral, a transferência financeira é um dos componentes formadores da renda, além dos salários, lucros, juros e aluguéis. Assim, se o Nordeste possui uma renda maior que seu PIB, provavelmente, a Região Sudeste apresenta uma renda inferior ao PIB, devido à transferência de renda entre as regiões promovida pelo governo federal (AMARAL FILHO, 2010, p. 55).

Enquanto isso, tomando como base os dados de 2000, os indicadores sociais nordestinos mostraram que a esperança de vida, ao nascer dessa população, teve um incremento relativo ${ }^{5}$ anual médio de apenas 0,5\%; o acesso à rede de água e de esgotamento sanitário teve uma progressão relativa média anual de 1,5\% e 0,7\%, respectivamente; a concentração de renda, de acordo com o Índice de Gini, é a segunda pior do país (ficando na frente apenas do Centro-Oeste), e a taxa de analfabetismo entre as pessoas com 10 (dez) ou mais anos de idade apresentou uma queda relativa de apenas $2,8 \%$ ao ano, sendo a evolução dessa última taxa apresentada inferior à nacional, indicando um aumentando ainda maior na disparidade no nível educacional inter-regional (INSTITUTO BRASILEIRO DE GEOGRAFIA E ESTATÍSTICA, 2011; 2012).

Em relação ao Índice de Desenvolvimento Humano Municipal (IDHM), indicador que apresenta resumidamente o nível de desenvolvimento social através de uma média aritmética entra as variáveis de educação, renda e longevidade, o Brasil passou de 0,612 pontos, em 2001, para 0,727, em 2010, enquanto o Nordeste, que foi, na década, a terceira região do País que mais gerou riqueza, apresentou o pior IDHM médio, com 0,659 pontos (PROGRAMA DAS NAÇÕES UNIDAS PARA O DESENVOLVIMENTO, 2013).

Percebe-se que, no Nordeste brasileiro, todos os indicadores sociais explorados evoluíram a menos da metade do PIB, com exceção dos indicadores do analfabetismo, que evoluiu um pouco acima da metade do indicador macroeconômico, mas abaixo da média nacional, podendo-se, assim, concluir que nessa região o crescimento econômico, entre os anos 2000-2010, não se desdobrou, na mesma proporção, em uma melhoria na qualidade de vida dessa sociedade.

Como já foi relatado, o Nordeste passou de uma região produtivamente hegemônica, no período colonial, para uma região periférica, já a partir do final do Império, situação que, nos anos 2000, pouco se reverteu, tanto no âmbito produtivo quanto social. Portanto, essa região necessita de políticas de desenvolvimento regional desenhadas a

\footnotetext{
${ }^{5}$ Termo utilizado para comparar a evolução dos dados tendo como base o ano de 2000.
} 
partir de uma visão em conjunto da economia e da sociedade, que, ao menos, garantam o crescimento econômico, a satisfação das necessidades básicas e a condição de cidadania com qualidade de vida para todos os brasileiros.

\section{Referências}

ALMEIDA, José E. de; ARAÚJO, José B. de. Um Modelo Exaurido: A Experiência da SUDENE. Teoria e Evidência Econômica, Passo Fundo, v. 12, n. 23, p. 97-128, nov. 2004.

AMARAL FILHO, Jair. O Nordeste Que Dá Certo. Caderno do Desenvolvimento, v. 5, p. 55-83, 2010.

ARAÚJO, Tânia B. de. Ensaios sobre o Desenvolvimento Brasileiro. Rio de Janeiro: Revan, 2000.

Por Uma Política Nacional de Desenvolvimento Regional. Revista Econômica do Nordeste, Fortaleza, v. 30, 1999.

BANCO DO NORDESTE BRASILEIRO. BNB. Quadro Macroeconômico Brasil e Nordeste 2000 a 2010. 2012. Disponível em: <http://www.bnb.gov.br/content/aplicacao/etene/ etene/docs/indicadores_macroeconomicos_brasil_nordeste_fev12.pdf $>$. Acesso em: 29 ago. 2013.

BRASIL. Ministério da Fazenda. Economia Brasileira em Perspectiva, 2010. Disponível em: <http://www.fazenda.gov.br/portugues/docs/perspectiva-economia-brasileira/ edicoes/Economia-Brasileira-EmPerspectiva-Jan-Mar-19-04-13.pdf>. Acesso em: 29 ago. 2013.

BRASIL. SUDENE. Contribuição da SUDENE ao Desenvolvimento do Brasil. Recife, 2013. Disponível em: <http://www.sudene.gov.br/sudene>. Acesso em: 29 ago. 2013.

COSTA, José M. Concentração e Desconcentração Industrial. 2012. Disponível em: <http://www.cofecon.org.br/noticias/artigos/16-artigo/2626-artigo-concentracao-edesconcentracao-industrial-no-brasil>. Acesso em: 29 ago. 2013.

FEITOSA, Cid O. Economia Sergipana: origem de desenvolvimento. Málaga: Universidad de Málaga, 2013.

FOLHA DE SÃO PAULO. Nordeste Concentra 59\% da População em Extrema Pobreza, diz IBGE. São Paulo, 2011. Disponível em: <http://www1.folha.uol.com.br/poder/913829nordeste-concentra-59-da-populacao-em-extrema-pobreza-diz-ibge.shtml>. Acesso em: 10 ago. 2013.

FURTADO, Celso M. Uma Política Nacional Para o Desenvolvimento do Nordeste. Novos Estudos Cebrap, São Paulo, v. 11, p. 12, dez. 1981.

GRUPO DE TRABALHO PARA O DESENVOLVIMENTO DO NORDESTE. Documento do GTDN. Revista Econômica do Nordeste, Fortaleza, v. 28, n. 4, p. 387-432, out./dez. 1997.

GUIMARÃES NETO, L. Trajetória Econômica de Uma Região Periférica. Estudos Avançados, v. 11, n. 29, p. 37-54, 1997. Disponível em: <http://www.scielo.br/pdf/ea/ v11n29/v11n29a03.pdf>. Acesso em: 29 ago. 2013. 
GUIMARÃES NETO, L.; BRANDÃO, Carlos A. A Formação Econômica do Brasil e a Questão Regional, 2009. Disponível em: <http://www.ufpa.br/epdir/images/docs/ paper41.pdf>. Acesso em: 29 ago. 2013.

INSTITUTO BRASILEIRO DE GEOGRAFIA E ESTATÍSTICA. IBGE. Censo Demográfico 2010. Rio de Janeiro, 2011. Disponível em: <http://www.ibge.gov.br/home/estatistica/populacao/censo2010/caracteristicas_da_populacao/resultados_do_universo.pdf>. Acesso em: 29 ago. 2013.

. Censo Demográfico 2010: Resultados gerais da amostra. Rio de Janeiro, 2012. Disponível em: <http://www.ibge.gov.br/home/presidencia/noticias/imprensa/ppts/00 000008473104122012315727483985.pdf>. Acesso em: 29 ago. 2013.

PRADO JÚNIOR, Caio. História Econômica do Brasil. Brasília: Brasiliense, 1994.

SINGER, Paul. Desenvolvimento e crise. São Paulo: Difusão Europeia do Livro, 1968.

SOUSA, Rainer. Apogeu e Crise. Disponível em: <http://www.brasilescola.com/ historiab/apogeu-acucar.htm>. Acesso em: 29 ago. 2013.

VEIGA, José E. da. Desenvolvimento Sustentável: o desafio do século XX. Rio de Janeiro: Garamond, 2010. 